
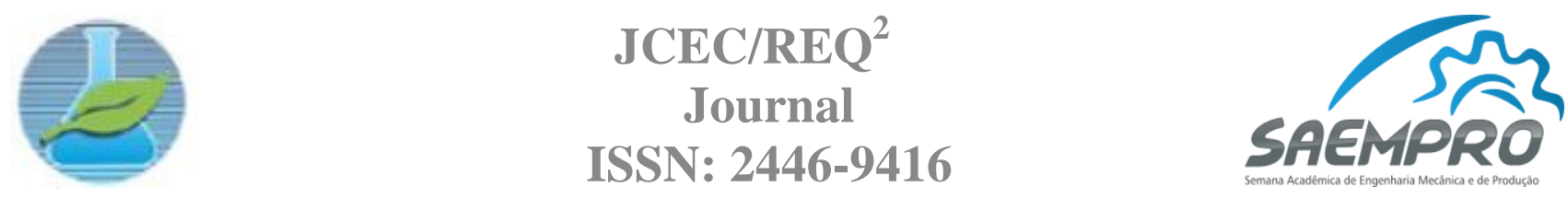

\author{
"EU, A INDÚSTRIA E O MUNDO" \\ 08 a 11 de novembro de 2016 no campus Viçosa da UFV \\ Departamento de Engenharia de Produção e Mecânica - DEP \\ Universidade Federal de Viçosa - UFV
}

\title{
ESTUDO DO EFEITO DO NÚMERO DE PÁS EM UM ROTOR DE BOMBA CENTRÍFUGA UTILIZANDO SIMULAÇÃO CFD
}

\author{
Lucas Calvi Piazzarolo \\ Universidade Federal de Viçosa, Departamento de Engenharia de Produção e Mecânica \\ $\mathrm{Ph}$. Rolfs s/n - 36570-000 - Viçosa - MG \\ lucas.piazzarolo@ufv.br
}

\section{INTRODUÇÃO}

As bombas centrífugas são máquinas operatrizes nas quais as forças que se desenvolvem na massa líquida são responsáveis pela movimentação desta (Cipolla et al.,2011). O fluido que entra na bomba recebe energia cinética do rotor (que realiza movimento rotacional), e a ação centrífuga do rotor acelera o fluido a uma alta velocidade, cedendo energia mecânica rotacioanal a este (Rajendran et al., 2012).

O principal componente deste tipo de equipamentos é o rotor, composto de um conjunto de pás ou palhetas que impulsionam o líquido que passa por ele, e onde a maior parte da transformação de energia dentro da bomba ocorre. Através da rotação deste, que gira com a mesma velocidade angular do eixo, são geradas as forças que são desenvolvidas na massa líquida. Alterações nas características físicas do rotor, como número de pás, ângulo de saída das pás, e diâmetro do rotor, por exemplo, possuem grande influência no desempenho final do equipamento, visto que a alteração desses fatores leva a uma mudança na quantidade de energia hidráulica disponível na saída do rotor, e assim, na quantidade de trabalho disponível que o fluido pode realizar (Rajendran, et al., 2012).

Uma das formas de avaliar o desempenho de uma bomba centrífuga é através da obtenção da curva característica da bomba, que representa graficamente o funcionamento do equipamento, e geralmente é obtida através de ensaios de bancada e fornecida em catálogos de fabricantes.

Para que o projetista alcance o desempenho máximo esperado do equipamento, muitos estudos e variações de projeto são feitas até que o modelo seja implantado. Porém, a construção de protótipos (modelos físicos) é, muitas vezes, inviável, devido a limitações financeiras e de tempo.

Com isso, nos últimos tempos, a Dinâmica dos Fluidos Computacional (CFD - Computer Fluid Dynamics) vem se destacando, pois, as simulações numéricas possuem um grande potencial para predizer o desempenho e fornecer um quadro completo do funcionamento do equipamento (Cipolla et al.,2011), antes da produção e implantação do sistema, gerando assim uma economia de tempo e recursos financeiros.

Esse trabalho buscou investigar, através de simulações CFD, a influência do número de pás do rotor de uma bomba centrífuga. Para isso, foram gerados dois modelos, um com 6 e outro com 10 pás, e ambos foram submetidos às mesmas condições de contorno.

\section{METODOLOGIA}

Para que a modelagem CFD pudesse ser feita, o primeiro passo foi a criação de um modelo físico, ou seja, uma geometria que representasse o fluido no interior do rotor da bomba centrífuga estudada. Após esta etapa, foi gerada a malha para o fluido de trabalho e inseridas as condições de 
contorno da simulação. Com a simulação pronta, uma nova geometria foi feita, apenas alterando o número de pás do rotor, a fim de analisar a influência que essa característica tem sobre o desempenho deste equipamento.

As geometrias dos modelos foram obtidas a partir do procedimento de cálculo apresentado por Henn (2012), para uma vazão nominal de $24 \mathrm{~m} 3 / \mathrm{h}$, altura manométrica de $8 \mathrm{~m}$ (referente ao ganho de pressão estática, apenas) e rotação de $1750 \mathrm{rpm}$. Suas especificações de desenho são:

- D4 (Diâmetro de Entrada): 56,5 mm;

- D5 (Diâmetro de Saída): 148,9 mm;

- $\quad \beta 5$ (Ângulo de Saída da Pá): $25^{\circ}$;

- b4 (Largura de Entrada): $21 \mathrm{~mm}$;

- b5 (Largura de Saída): 10 mm;

- z (número de Pás): 6 ou 10;

- Espessura da Pá: 3 mm;

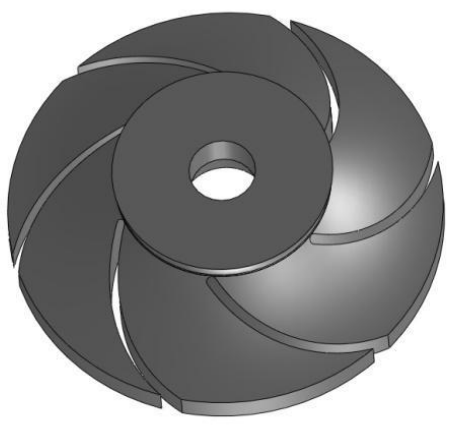

Figura 1 - Fluido no Rotor de 6 pás.

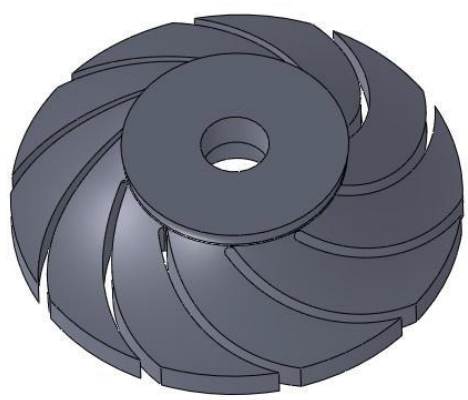

Figura 2 - Fluido no Rotor de 10 pás.

Após a construção da geometria que representa o fluido que será utilizado pela ferramenta de CFD, o próximo passo é a geração da malha que irá representar o volume de controle do escoamento. Para a geração da malha, foi utilizado o software Meshing ${ }^{\circledR}$, dentro da plataforma ANSYS ${ }^{\circledR}$. Finalmente, as condições de contorno inseridas foram de pressão atmosférica na entrada do rotor e vazão volumétrica variável na saída do mesmo. A variação da vazão foi feita para que as curvas características e de rendimento pudessem ser traçadas. O fluido de trabalho utilizado foi água a 25 graus Celsius, e a velocidade de rotação escolhida foi de $1750 \mathrm{rpm}$.

\section{RESULTADOS}

A partir das simulações dos dois rotores, foram obtidas as curvas características e de rendimento hidráulico de ambos os rotores. 


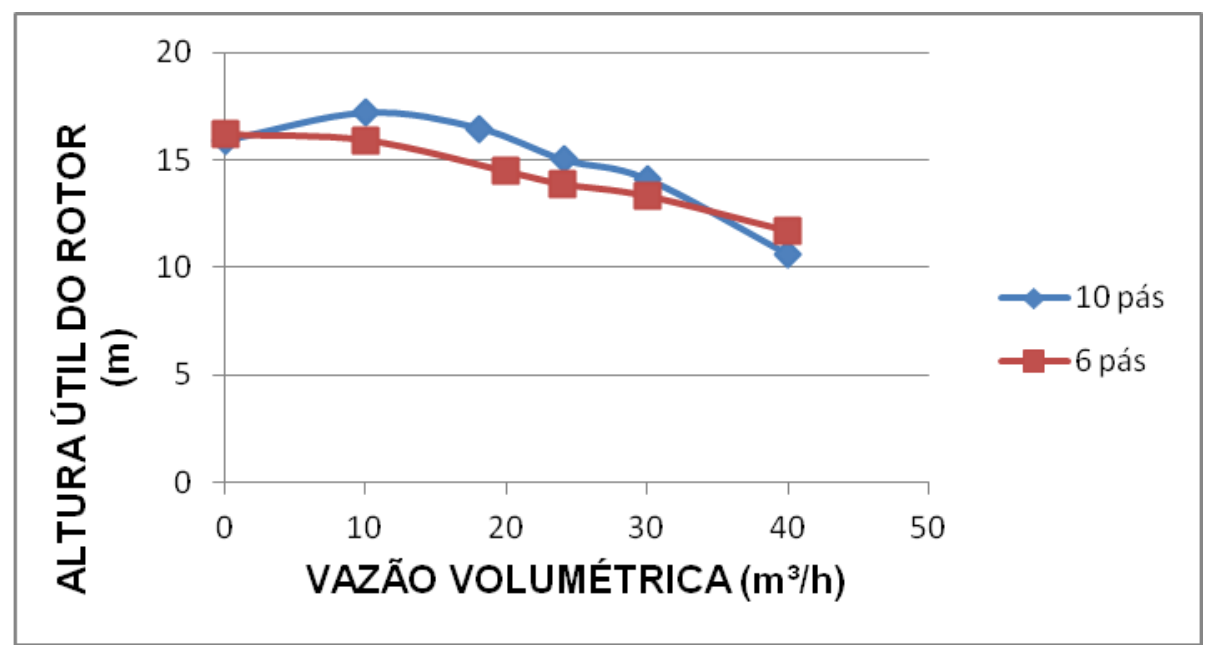

Figura 3 - Curvas Características

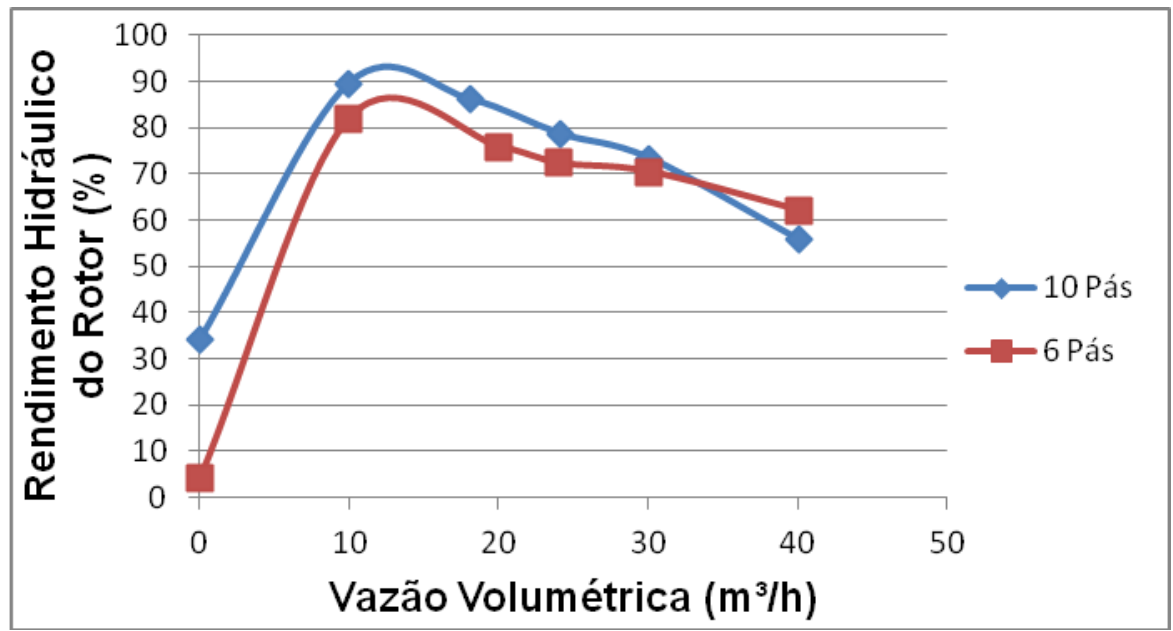

Figura 4 - Curvas de Rendimento Hidráulico

\section{CONCLUSÕES}

O principal objetivo do trabalho foi o de obter a curva característica e curva de rendimento hidráulico dos dois rotores. Comparando as curvas características e as curvas de rendimento hidráulico dos rotores, o modelo com 10 pás apresentou melhor desempenho, com maior altura útil e rendimento hidráulico superior na maior parte das vazões, o que também era esperado teoricamente. O rotor com 6 pás mostrou-se mais eficiente apenas para vazões muito elevadas, que não seriam utilizadas em um projeto real da bomba estudada.

Finalmente, pôde ser constatada a eficiência das ferramentas de CFD como parte fundamental no projeto de uma bomba centrífuga, pois permite aos projetistas preverem seu desempenho, e assim desenvolverem o melhor projeto possível antes de qualquer processo de fabricação. Isso possibilita enconomia de recursos com fabricação, teste de modelos e de tempo em um projeto real.

\section{REFERÊNCIAS}

Cipolla, E.A.L., 2011, "Avaliação da Distribuição de Velocidades em Uma Bomba Centrífuga Radial". Henn, E. A. L., 2012, "Máquinas de Fluido", $3^{\mathrm{a}}$ Edição, Editora UFSM. 495 p.

Rajendran S., Purushothaman, K., 2012, "Analysis of a centrifugal pump impeller using ANSYS-CFX". International Journal of Engineering Research \& Technology (IJERT), Vol. 1 Issue 3. 